\title{
AN ACCESSORY ORGAN OF THE CIRCULATORY SYSTEM IN SEPIA AND LOLIGO
}

\author{
By J. S. Alexandrowicz \\ The Plymouth Laboratory \\ (Plates I and II and Text-figs. I-3)
}

Around the posterior pallial vessels in Sepia officinalis a ball-shaped structure has been found which is evidently an accessory organ of the circulatory system. It has also been observed in Loligo forbesi, but not in the two decapods examined, Eledone cirrhosa and Octopus vulgaris. The following description is based on the study of Sepia. In an account of the nerves supplying the accessory organ some observations are also included on the innervation of the blood vessels.

\section{METHODS}

The general structure of the organ was examined on preparations fixed in Bouin's mixture and stained with Azan. Methylene blue was useful for its study in situ and for studying the arrangement of its muscles in whole mounts, but rarely gave information of value on its nerve elements. Silver methods proved to be much superior in this respect. Of these Cajal-Schultze's method was chiefly used for the study of nerves in whole mounted preparations. A modification which gave good results consisted in fixing the tissue in the mixture indicated below, instead of in formol. The whole procedure was as follows:

(I) Fixation in:

$\begin{aligned} & \text { methanol } 85 \text { parts } \\ & \text { formol }\end{aligned}$ I5 parts . . . . . . . . . . $24 \mathrm{~h}$

acetic acid 5 parts

(2) Washing in $70 \%$ alcohol . . . . . . $\mathrm{I}_{2 \mathrm{~h}}$

Washing in distilled water $. \quad . \quad . \quad . \quad . \quad . \quad . \quad 24 \mathrm{~h}$

(3) Treatment with $0.25 \%$ sodium hydroxide solution . . . $24 \mathrm{~h}$

(4) Washing in running water . . . . . . . $4 \mathrm{~h}$

Washing in distilled water $. \quad . \quad . \quad . \quad . \quad . \quad . \quad 18 \mathrm{~h}$

(5) Impregnation with 3\% silver nitrate solution . . . . 24-48 h

(6) Reduction in:

stock solution (hydroquinone $2 \mathrm{~g}$, formol 5 c.c., distilled water 95 c.c.) 3 c.c.

distilled water 97 c.c. $\}$. $\cdot$. $\quad . \quad \cdot \quad \cdot \quad \cdot \quad 5-15 \mathrm{~min}$

(7) Washing, toning, etc.

It should be noted that preparations fixed in the above methanol mixture become so opaque that the darkening of the nerves during the process of reduction is difficult to follow, especially in thicker preparations, since the deeper situated nerves usually stain brown rather than black. Consequently, the results cannot be assessed before the 
tissues become cleared in xylol; one should not therefore reject preparations in which the nerves in the earlier stages are almost or even completely invisible.

Fixation with the methanol mixture ${ }^{1}$ proved also suitable for preparations to be stained with Bodian's method.

Cajal's silver impregnation was applied according to the procedure recommended by Sereni \& Young (1932).

\section{STRUCTURE OF THE ACCESSORY ORGAN}

The organ in question may be compared to a turban or a ball of wool in which the strands are wound in various directions (Pl. I, fig. I). For the sake of brevity it will be referred to hereafter as the ball. It measures in mediumsized animals about $2 \mathrm{~mm}$ in diameter and thus can be seen with the naked eye. It is situated on the inner surface of the mantle close to the insertion of $\mathrm{m}$. retractor branchiae (Text-fig. I). At this point the posterior pallial artery enters the mantle and the vein comes out of it. Therefore when following the artery, which usually is easier to identify than the vein, one must arrive at the point where it pierces the ball-shaped structure which, as shown in Text-fig. 2, lies in a small depression of the mantle muscles. It is somewhat obscured from view by overlying tissue and does not stand out distinctly, but in methyleneblue preparations as well as in sections it appears well delimited (Pl. I, figs. I, 2).

The loosely arranged muscle bundles of the ball are imbedded in connective tissue consisting of jelly-like substance with collagen fibres and scattered cells in it. The consistency of the ball is like that of a very soft rubber ball, yielding to slight pressure and regaining its shape when the pressure is released. This can be observed under the dissecting microscope by touching the ball with the needle. Because of this soft consistency the outlines of the ball in fixed preparations are often irregular, being evidently distorted by the pressure of harder tissues around it. It seems also that there may be variations in its shape in different individuals: it can be more or less flattened and also the depression of the mantle muscles in which it is situated can be deeper or shallower.

The muscle bundles of the ball anastomosing with each other run in various directions, but most of them take a circular course (Text-fig. 2). Those situated nearer the periphery follow the curvature of the ball, others, running deeper, pass between the artery and the vein and many of them curve round each of these vessels. The muscles around the artery are more numerous and encircle the whole of its portion included in the ball, whereas the vein in its deeper portion, i.e. that situated farther from the inner surface of the mantle, is not surrounded by the muscle fibres. It should be emphasized that there is no connexion between the muscles of the ball and those of the tunica media of the artery and the vein, the two systems being separated by the connective

1 The substitution of methanol for ethanol for fixation of nerve tissue in alcohol-formolacetic acid mixture was suggested by David (1955). His mixture consists of methanol 80 parts, formol to parts, and acetic acid ro parts. 


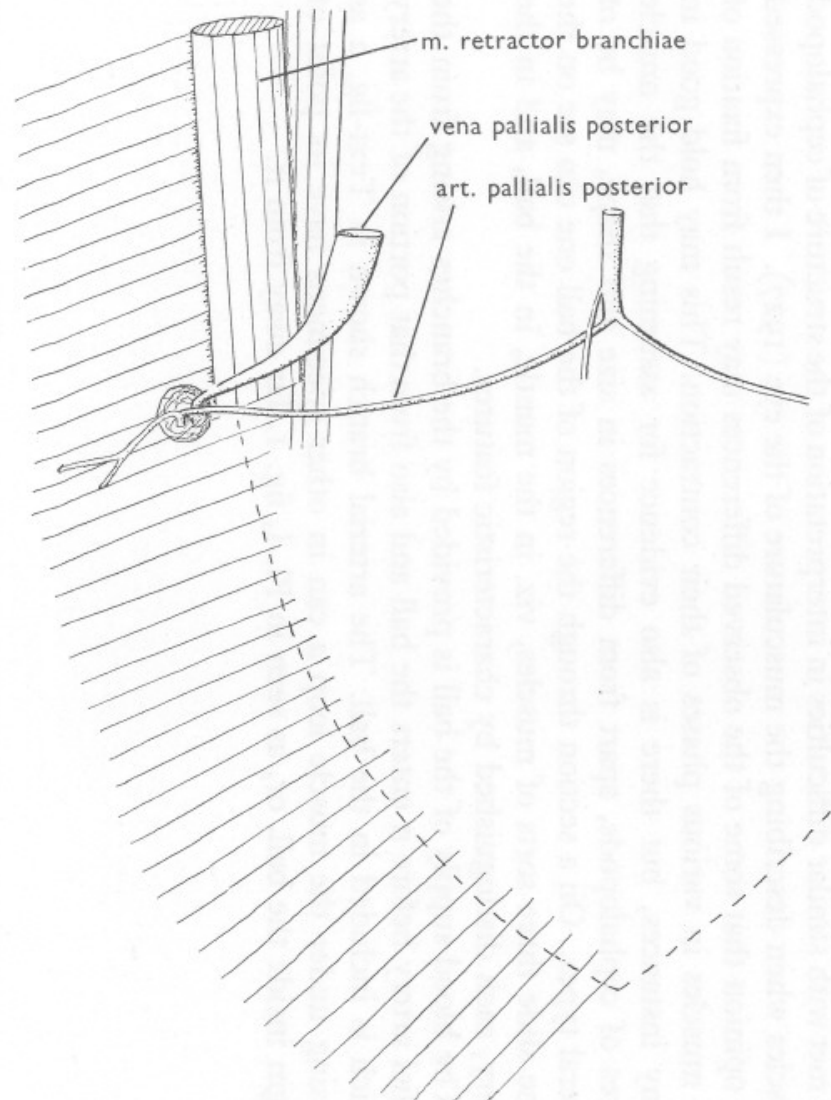

Text-fig. I. Sepia officinalis. Diagram showing the position of the accessory organ on the inside of the mantle. Interrupted line indicates the outline of the shell covered by the mantle muscles.

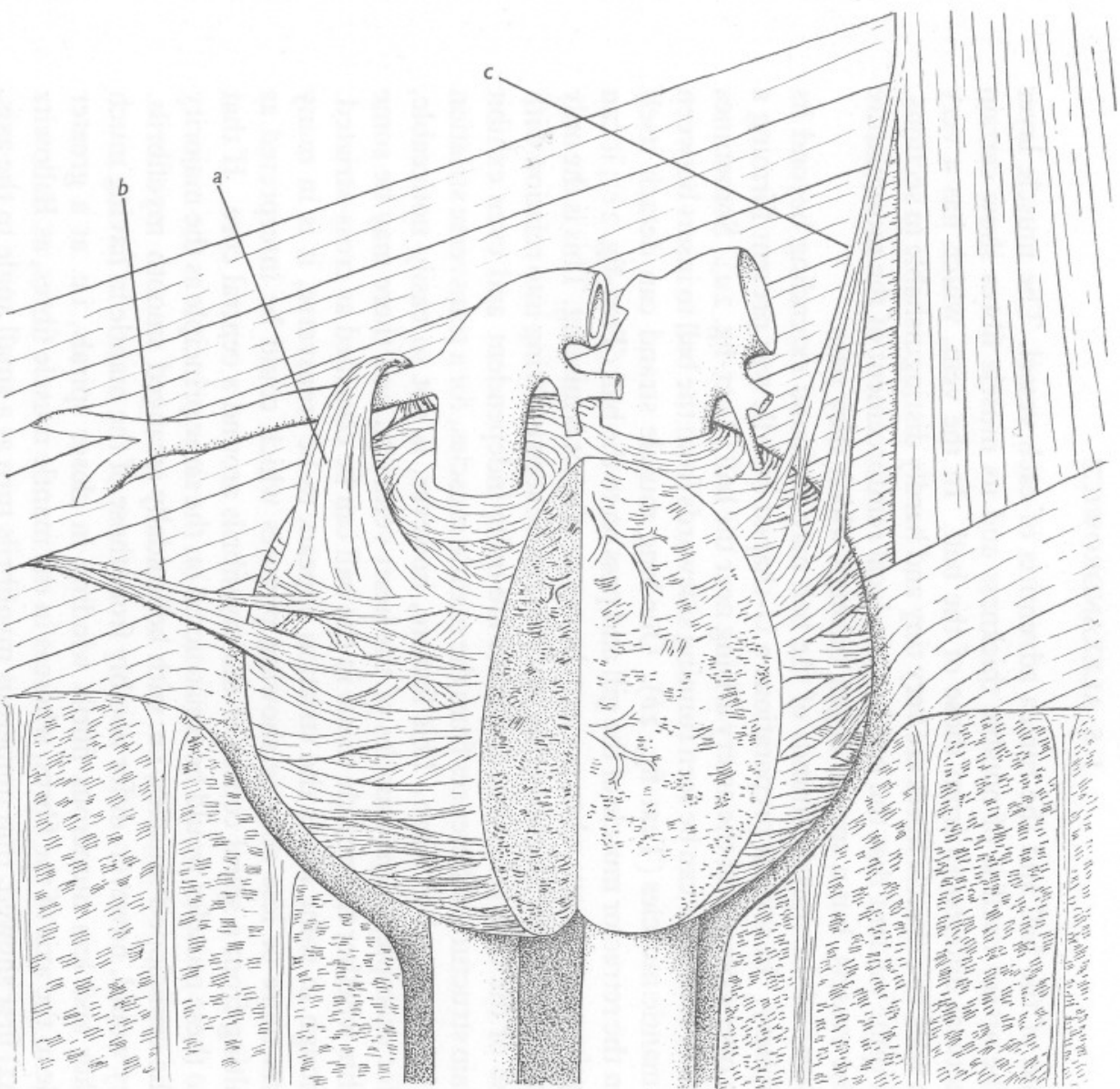

Text-fig. 2. Sepia officinalis. Semi-diagrammatic view of the accessory organ of the right side lying in a slight depression of the mantle muscles; a segment is cut out of its wall to show the course of the muscles in it; $a$, muscle bundle passing over a branch of the posterior pallial artery; $b$, muscle bundle inserting between the mantle muscles; $c$, muscle bundle from the $m$, retractor branchiae. 
tissue of the ball and the tunica adventitia of each vessel. The muscle layer of the artery itself is of notable thickness and its muscle fibres show certain structural differences from those of the ball. In the vein, which has a very thin wall, the muscle fibres are very tiny and hardly distinguishable in sections. It is quite evident that the ball is not a local reinforcement of the musculature of the vessels, but a special organ through which they pass.

Some of the muscle strands of the ball may be found extending beyond its periphery. In several preparations a $U$-shaped bundle was present forming a loop over a branch of the artery arising near the ball (Text-fig. 2a). Sometimes small muscle slips can be seen running sidewards from the ball to insert between the mantle muscles (Text-fig. $2 b$ ). One long muscle strand can detach itself from the retractor muscle of the gill and pass on to the ball (Text-fig. $2 c$ ); it can be quite conspicuous when present, but more often it is missing. This is the only instance when the neighbouring muscles can be seen entering into relation with those of the ball, otherwise the latter are quite independent and even exhibit certain structural differences from the mantle muscles, for a transverse striation can be observed in them. This feature, however, is not so easily noticeable, as, for example, in the muscles of the heart ventricle, and there may be some doubts whether the muscle tissue in the ball can be classified as cross-striated. Although in some fibres the striation appears to be transverse, it is in many others more or less oblique showing pictures which could be interpreted as resulting from a spiral course of the myofibrils around a central core. If that be so these muscles would be constructed on the same principle as the majority of the cephalopod muscles, i.e. with helicoidally arranged smooth myofibrils. They would, however, differ notably from those of the mantle in having much thicker and less numerous fibrils winding in closer spirals, i.e. at a greater angle to the axis of the fibres, whereas in the mantle muscle fibres, as Ballowitz (I892) first showed, thin numerous myofibrils turn at a small angle to the axis, sometimes almost parallel with it.

I met with similar difficulties in interpretation of the structure of cephalopod muscles when describing the musculature of the eye (1927). I then expressed the opinion that some of the observed differences may result from fixation of the muscles in various phases of their contraction. This may hold good in many instances, but there is also evidence for assuming that the muscle fibres of cephalopods, apart from differences in size and shape, may be of several types. On a section through the region of the ball one can see on the same slide three sorts of muscles, viz. in the mantle, in the ball, and in the artery, each distinguished by characteristic features.

The blood supply of the ball is provided by the branches arising from the pallial artery before it enters the ball and also from that portion of the artery which is included in the ball. The arterial branch shown in Text-fig. 2 as passing under the muscle loop $a$ can in other specimens have its point of origin inside the ball, or, as seen in P1. I, fig. I, far away from it. 
In Loligo forbesi the accessory organ is more elongated than in Sepia, forming a sort of muff around the artery, while around the vein it is reduced to a broad ring. The muscles form a compact layer with very little connective tissue between the muscle bundles. This seems to indicate that in Loligo the organ is adjusted to a more powerful action than in Sepia, although its diameter in animals of comparable size may be the same or even smaller.

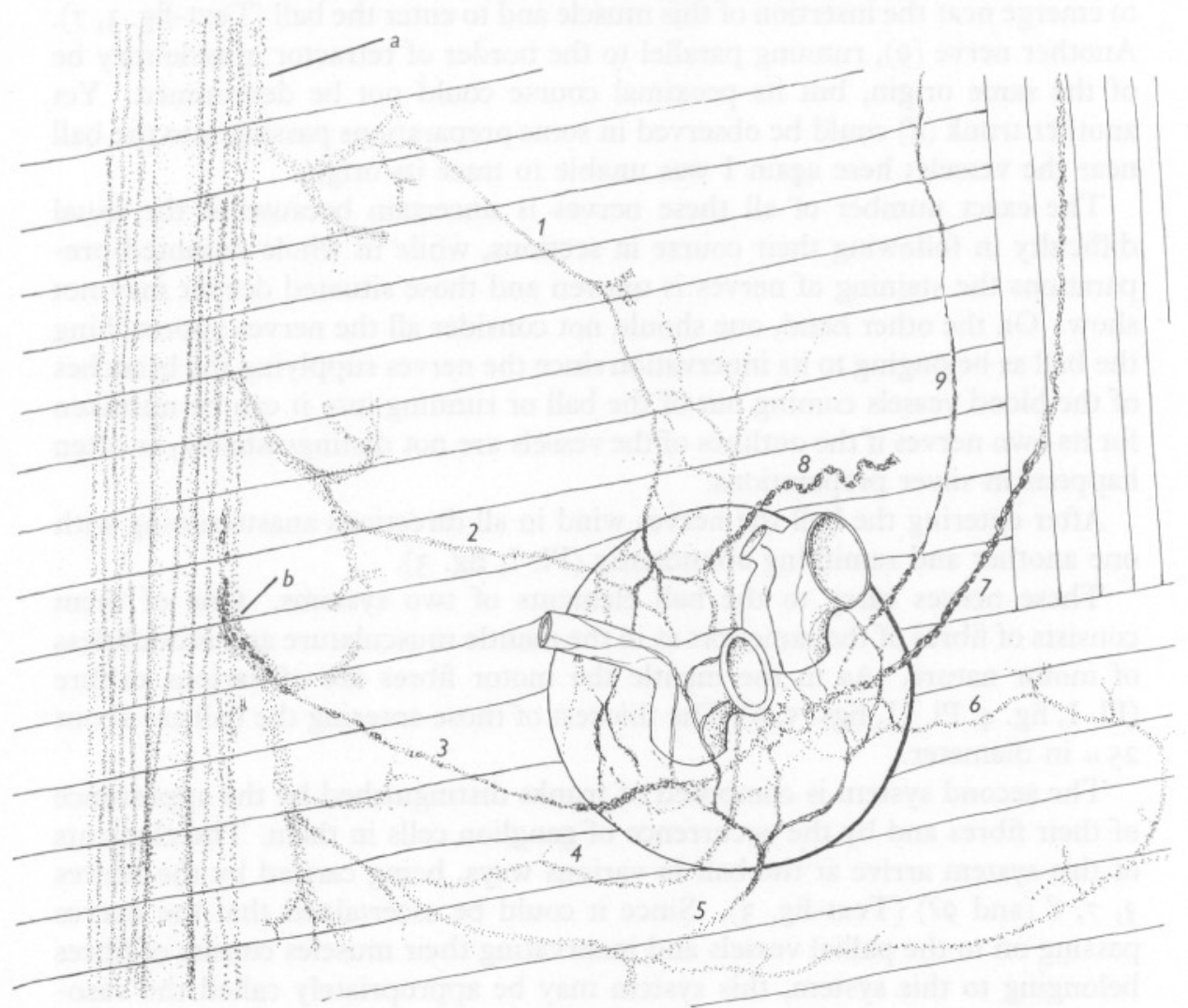

Text-fig. 3. Sepia officinalis. Innervation of the accessory organ seen from inside of the mantle. $a$, one of the stellar nerves; $b$, location of a large group of ganglion cells of the vasomotor system; $I-6$, nerves branching from the mantle nerves; 7 , nerve emerging from the m. retractor branchiae through which it runs from the cardiac ganglion; 8 , 9 , nerves of uncertain origin. Nerves $3,7,8$, (9?), carry vasomotor elements.

\section{NERVES}

The nerves approach the ball from various directions and run at various levels. Most of them (Text-fig. $3, I-6$ ) branch from the nerves of the neighbouring mantle muscles which arise from a big trunk, one of the main nerves of the mantle, passing near the ball $(a)$. It is worthy of note that one and the same 
nerve and even the same fibre may branch both within the ball and in the mantle muscles. Sometimes a nerve as 4 in the figure, situated at a deeper level may be seen piercing the ball to run further in the mantle and distributing its branches through its whole course.

Other ball nerves are of different origin: one of them comes out of the cardiac ganglion, penetrates the retractor muscle of the branchia and runs in it to emerge near the insertion of this muscle and to enter the ball (Text-fig. 3, 7). Another nerve (9), running parallel to the border of retractor muscle may be of the same origin, but its proximal course could not be determined. Yet another trunk ( 8 ) could be observed in some preparations passing into the ball near the vessels; here again I was unable to trace its origin.

The exact number of all these nerves is uncertain because of the usual difficulty in following their course in sections, while in whole mounted preparations the staining of nerves is uneven and those situated deeper may not show. On the other hand, one should not consider all the nerves approaching the ball as belonging to its innervation since the nerves supplying the branches of the blood vessels coming out of the ball or running into it can be mistaken for its own nerves if the outlines of the vessels are not distinguishable, as often happens in silver preparations.

After entering the ball the nerves wind in all directions anastomosing with one another and ramifying abundantly (Pl. I, fig. 3).

These nerves carry to the ball elements of two systems. One of them consists of fibres of the same sort as in the mantle musculature and is doubtless of motor nature. As in the mantle the motor fibres are of various calibre (Pl. I, fig. 4, Pl. II, figs. 5, 6). The thickest of those entering the ball are about $25 \mu$ in diameter.

The second system is composed of trunks distinguished by the appearance of their fibres and by the occurrence of ganglion cells in them. The elements of this system arrive at the ball in various ways, being carried by the nerves 3, 7, 8 (and 9?) (Text-fig. 3). Since it could be ascertained that the nerves passing on to the pallial vessels and innervating their muscles consist of fibres belonging to this system, this system may be appropriately called the vasomotor. The characteristic feature of its fibres is their comparatively small calibre; the stoutest of them measure about $3 \mu$ only and are thus much thinner than some fibres in the motor nerves even in their remote subdivisions. There is therefore a much greater uniformity in appearance of a vasomotor trunk although its fibres are not exactly of the same thickness (P1. II, fig. 7). When such a trunk associates with a motor nerve the elements of the two systems are sometimes well distinguishable especially in preparations stained with Bodian's method (P1. II, figs. 8, 9). Cajal's silver impregnation, although showing muscle nerves in cephalopods very well, proved to be less suitable for this purpose. 


\section{NERVE CELLS}

The nerve cells associated with the bundles of vasomotor fibres form either groups of a smaller or greater number of cells, or rows accompanying the fibres for a longer distance. The largest of the cell groups met with was situated in the big mantle nerve at the point where it passes near the ball (Text-fig. $3 b$ ). Smaller groups or single cells can occasionally be seen in the same nerve more anteriorly. All these cells belong to a vasomotor trunk which runs in the big mantle nerve and leaves it with one of its thicker branches to pass on to the ball (Text-fig. 3, 3; Pl. II, fig. 8). In the latter part of its course this trunk is accompanied by few motor fibres and carries few nerve cells, but near the ball and after penetrating into it it contains a row of cells huddled together (Pl. II, fig. I0). It can be followed for a longer distance within the ball, and when it is cut transversely one or two nerve cells can be seen in each section.

Another nerve belonging to the vasomotor system is that one which runs through the $\mathrm{m}$. retractor branchiae (Text-fig. 3, 7). This nerve appears to convey to the ball exclusively the vasomotor elements and it could be observed in serial sections that it carries nerve cells in its whole course. The nerve 8 which enters the ball near the blood vessels is also a ganglionated trunk. It is possible that the nerve 9 running parallel with the border of the retractor muscle is also of the same sort, but I am uncertain on this point.

The ganglion cells are spheroidal or ovoidal in shape. Their size ranges between 15 and $60 \mu$. In favourable stained preparations fibrillar structures can be seen in them, some very fine, other much coarser, similar to those described by several authors (Gariaeff, I909; Jakubski, I915; Bogoraze \& Cazal, I944). There is no unanimity in interpretation of these structures and from my personal observations I have been unable to come to a definite opinion as to their nature and mutual relations. This interesting problem needs special study.

The nuclei of the nerve cells are a little larger and less elongated than those in the muscles and in the connective tissue; these differences are helpful in recognizing the nerve cells when their cytoplasm does not show well.

The processes of the cells could not be made clearly visible with either of methods employed. Only exceptionally do they stain with methylene blue, and in such instances the more distinctly stained cells appeared to be unipolar (P1. II, fig. II). Some have appearance of being bipolar, but I am not certain whether cells of this type actually occur. In spite of the failure to obtain clear pictures of the cells with their processes distinctly stained there can be no doubt as to their nervous nature so far as the cells of the above indicated size-range are concerned. As to some smaller cells which can be sometimes seen in the vasomotor trunks which do not stain well and in which only their nuclei are visible, I have not been able to decide whether they are nerve cells of the same sort differing only in size, or nerve cells of some other sort, or not nervous at all. 


\section{COMPOSITION OF THE NERVES}

From the foregoing observations it follows that the nerves entering the ball can be either of mixed composition, i.e. carrying both motor and vasomotor trunks, or consist of elements of one system only. In the ball itself they are so intermingled that it is practically impossible to distinguish in whole mounted preparations the elements of each system; only those trunks which pass on the wall of the vessels can be identified as consisting entirely of vasomotor fibres. It is from the study of serial sections stained with Bodian's method that some information about the composition and distribution of the nerves within the ball could be obtained. In such sections it can be seen that the ganglion cells are present in two or three trunks as long rows which can be followed from the periphery up to the axial region of the ball while the bundles of vasomotor fibres associate with many thicker and thinner motor nerves (Pl. II, fig. 9). It can also be seen how the vasomotor fibres passing on the vessels separate from such mixed bundles, but it is not easy to find out whether the vasomotor elements take some part in the innervation of the muscles of the ball itself. As this question touches upon the problem of the finer innervation of cephalopod muscles, some observations on this subject may be inserted here.

The cardinal point of this problem is how many nerve fibres having discrete physiological function end on muscle units. The picture of muscle innervation in cephalopods is unfortunately much more complicated than, for example, in arthropods for several reasons; first, the number of neurons supplying comparable portions of musculature is in cephalopods many times greater; secondly, the nerves ramifying in the muscles run in various directions exchanging fibres with one another, and thirdly, many fibres of stouter calibre, besides dividing into branches gradually diminishing in thickness, may give off at various points of their course very thin fibres which ramify on the muscles situated near the point of their origin or join other branches. Consequently, the same fibre may have its terminations on muscle fibres distant from one another, the fact underlined also by Graziadei (I960) who studied the innervation of the fin in Sepia. Furthermore, one must be very cautious, when seeing a trunk consisting of thick and thin fibres, to regard all the thin ones as being of some special kind because a part of them may be nothing other than branches of a thick fibre of some neighbouring trunk. On the other hand, considering the fact that each of the mantle nerves coming out of the stellate ganglion has a mixed composition conveying one giant fibre and many thicker and thinner fibres, it must be expected that these various elements will be represented in the subdivisions of the main nerves. It must, however, be taken into consideration that not all fibres of the main nerves supply the muscles since, as Young's experiments have shown (Sereni \& Young, 1932), there are in the stellar nerves some fibres which run not towards the muscles but towards the stellate ganglion. The fact that the vasomotor elements can travel with the mantle nerves 
makes the picture even more complicated for it will be very difficult to trace their paths. They can be fairly easily distinguished in favourable conditions, but the identification of smaller vasomotor bundles without the accompanying nerve cells among fibres of other origin can be practically impossible.

As the stellar nerves carry giant fibres it is evident that the branches of the latter take part in the innervation of the mantle muscles, but they cannot be distinguished in the subsequent subdivisions from the ordinary motor fibres. It is true that in the nerves ramifying among the muscles up to those giving off finest perceivable elements two fibres can be very frequently seen which could suggest that one of them derives from the giant fibre. Not uncommonly a third fibre can be met with, but there is no adequate evidence whether this is a constant element of the muscle innervation.

Thus the results of histological investigation do not give a clear picture of the nerve supply of the mantle muscles: they allow it only to be stated that these muscles have most probably a double innervation and that the presence of a third element taking part in it is not excluded. Such a vague statement is of course unsatisfactory: as in so many instances in which no certainty can be reached because of the limitations of the light microscope and of the usual histological methods, there is nowadays hope that electron microscopy might give some help.

As to the intimate relations of the terminal filaments with the muscle fibres I must repeat my earlier expressed opinion (1960) that the small knobs or plaques frequently seen at the end of the fibres in silver impregnated preparations are artefacts produced at the points where the staining stops and do not necessarily indicate the true endings of fibres which in the best preparations appear to fade out without making any special endorgans. What are their endings in submicroscopical scale is another question.

Returning to the problem of the innervation of the ball it should be recalled that in the nerves entering this organ fibres of both motor and vasomotor system are present. They can be more or less easily distinguished in the thicker nerves. In their subdivisions, however, all the fibres become thinner and it becomes more and more uncertain whether the motor fibres are accompanied by the vasomotor fibres. One may only suppose that it is so because the preterminal branches look sometimes as if they were composed of more fibres than the corresponding branches in the mantle. Thus, although the picture of the finest observable terminations affords no decisive evidence, it appears probable that the muscles of the ball are supplied by elements of both systems.

\section{FUNCTION OF THE ACCESSORY ORGAN}

As regards the function of this muscular ball surrounding the pallial vessels the idea that first suggested itself was that it must be an organ helping the propulsion of the blood. Before the details of its organization were known it 
seemed strange that no rhythmic contractions in it could be noticed, while in the same specimen the pulsations of the hearts and of the big veins were quite manifest. After better acquaintance with the structure of the organ it has become evident that the contractions of its muscles can produce only the constriction of the pallial vessels and consequently they cannot have any other effect than of reducing or stopping the blood flow in them. This being so, the question to be answered is in what circumstances these muscles would come into action. The fact that their motor innervation is a part of the motor system of the mantle leads to the assumption that their contraction must take place each time when the mantle muscles contract vigorously, as in the escape reaction. Further, it can be assumed that the resulting constriction is instrumental in attenuating the repercussion of the sudden change in blood pressure on the proximal portions of these vessels. As regards the vein it is understandable that a large amount of blood driven rapidly out of the mantle by its powerful contractions could produce a harmful pressure on its wall. It is true that the proximal portion of this vein has a widened lumen, but its wall is very thin and its muscle coat is poorly developed compared with that of other big veins. It is evident that an organ compressing the vein at the point where it emerges out of the mantle can give an adequate protection.

At first sight, the need of such an organ for the artery is not apparent since this vessel has a thick wall well equipped with its own muscle tissue. It should, however, be taken into consideration that the muscles of the tunica media of the arteries are presumably adjusted for regulation of the blood flow in larger areas of the body and therefore, when a local constriction is required, a special organ is necessary. It is further obvious that for compression of the artery a greater amount of muscle tissue is needed than for the vein and in fact this difference, especially in Loligo, is well accentuated. Other structural differences of these organs in the two species may have some bearing on their mode of action. In Sepia, the looser arrangement of muscle fibres embedded in a tissue of jelly-like consistence, seems to indicate that this organ compresses the vessels in the manner of a soft rubber ball, whereas in Loligo the strong compact muscle muff looks as if devised for a sudden firmer grip. In any case the action of the muscles leads to the decrease or interruption of the blood flow into the part of the mantle supplied by the posterior pallial artery. It should be mentioned that the anterior pallial vessels are not provided with a similar accessory organ: there must evidently be some differences in conditions of blood circulation in the posterior and anterior regions of the mantle.

There are certain histological features of this organ from which we may perhaps infer something regarding its functional relations. The fact that its muscles have a common innervation with those of the mantle indicates, as pointed out before, that they are functionally linked with them. On the other hand, they form an anatomically independent system and even exhibit certain differences in their structure. It is, moreover, possible that they have an 
additional nerve supply from the vasomotor system. If this is actually so they must receive the same impulses as the muscles of the vessels and consequently the organ in question would be adapted to two kinds of action, one synchronized with the rapid contractions of the mantle, the other with the contractions of the muscle coat of the pallial vessels. It may be that the independence of the ball muscles and the particular features of their structure relate to this double mode of function.

\section{OBSERVATIONS ON THE INNERVATION OF THE BLOOD VESSELS}

The occurrence of the nerves running to the blood vessels in cephalopods is a known fact. Already in 1866 Chéron described one of these nerves branching from the visceral trunk and passing on to the vena cephalica. In the work on the nervous system in Sepia (Hillig, I9I2) and in Octopoda (Pfefferkorn, I9I5) the nerves to the cephalic vein have been described in more detail and some others to the blood vessels have been mentioned. Later Thore (I939) has given more precise information about the origin of the nerves to the cephalic vein. In the papers of some other writers one can occasionally find remarks about the occurrence of the nerves to the vessels, but a comprehensive picture of this system in cephalopods is still wanting. From what is known it appears that most of these nerves arise from the visceral ganglia either directly or with the visceral trunks; some, however, are known to take origin in other parts of the central nervous system, e.g. the nerves supplying the suborbital sinus in Octopus, which according to Boycott \& Young (1956) issue from the subpedunculate nerve "that can be traced to a lobe at the hind end of the supraoesophageal ganglia, below the vertical lobe as Thore has described'. There is also an observation, but of much less certain character, concerning the origin of the nerve to the aorta cephalica from the ganglion buccale inferius (Pfefferkorn, 1915).

Although only few of these trunks running to the vessels have been observed there can be no doubt that all the blood vessels are supplied with nerves abundantly ramifying in their muscular coat; even the capillaries can be seen accompanied by fine nerve filaments (Alexandrowicz, I928). It has, moreover, been observed that the nerve supply of certain vessels can be particularly conspicuous, evidently in relation with the stronger development of its muscles; this is so with the innervation discovered by Boycott \& Young in the blood sinus of the Octopus eye.

Present observations have revealed the fact that in the vasomotor nerves running to the posterior pallial vessels groups of nerve cells are included. As the processes of these cells do not stain distinctly it is impossible to say which of the nerve fibres in the vessels are derived from these peripheric cells and which from those situated in the higher centers. It may even be supposed that in the preparations examined the axons of the peripheric cells remain unstained 
in their whole length and that all the fibres visible in the nerve bundles are of central origin. However, in consideration of the fact that in many neurons of cephalopods, as well as of some other animals, the refractory behaviour to staining of the initial portion of the axon is of common occurrence, it seems more probable that these cell processes become stainable at some distance from the cells and that the fibres seen in the trunks of the vasomotor system are actually of double origin. They do not, however, exhibit features that would make the distinction of the two sets of fibres practically possible. It is true that, as stated above, these fibres are not of the same thickness, but the differences, being of graded character, cannot be a criterion of their different provenance.

The nerve cells of the vasomotor system have been observed by the present writer in a fragment of this system only. Earlier Thore (1939) mentioned their presence in Sepia in one of the nerves to the cephalic vein (called by him, after Hillig, nervus venae cavae anterior). It can be presumed that such cells are present in other regions of the body, but in view of the fact that in order to obtain more reliable information the study of serial sections is necessary, a good deal of work will be required until an accurate picture can be drawn of the origin and course of the vasomotor trunks and of the distribution of the nerve cells in them. ${ }^{1}$ It is now known that the vasomotor trunks can associate with the big mantle nerves. As yet their presence has been ascertained in one of these nerves, but it is possible that the others carry such elements too. During previous research on cephalopods I occasionally saw ganglion cells in the mantle nerves stained with methylene blue. It seemed to me then that they were cells which normally should be in the ganglion, but somehow during the development remained outside it. It is possible that such stray elements do exist, but in the light of the recent findings it appears probable that such cells might belong to the vasomotor system. When therefore the mantle nerves are subjected to physiological experiments it will be advisable to take into account the possible occurrence of ganglion cells in them.

I wish to express my sincere thanks to Dr F. S. Russell, F.R.S., Director of the Plymouth Laboratory, for his kindness and hospitality, and for his help in preparing the manuscript. I am indebted to the Royal Society for a grant enabling me to continue my scientific work.

\footnotetext{
${ }^{1}$ Preliminary examination of the proximal portion of the visceral nerves has shown that they contain groups of cells looking like those in the vasomotor trunks described above. Besides, there are, travelling with the visceral nerves, ganglionic trunks composed of nerve cells of different character. The axons of these cells form the thick nerves running to the cephalic vein. They are obviously not vasomotor in nature for they pass through the muscle layer without coming into relation with the muscle fibres. These nerve elements are being investigated and will be the subject of a later publication.
} 


\section{SUMMARY}

An accessory organ of the circulatory system has been found in Sepia officinalis and Loligo forbesi, situated on the inner surface of the mantle around the posterior pallial vessels. It is spheroidal in shape and consists chiefly of muscle fibres forming bundles anastomosing with one another, most of them taking a general circular course round the artery and the vein. In Sepia the muscle bundles are more loosely arranged, being imbedded in connective tissue of soft consistency; they are not continuous either with the musculature of the vessels or with that of the mantle, and show certain structural differences from them.

The nerves approaching this organ from various directions carry elements of two systems: ( $a$ ) fibres given off by the branches innervating the neighbouring mantle muscles; $(b)$ elements of the vasomotor system; these are 3 (or 4?) trunks consisting of fibres of small calibre and containing groups or rows of ganglion cells. One of these trunks associates with one of the main mantle nerves, another runs through the retractor muscle of the branchia. Within the accessory organ they intermingle with the motor fibres, but the nerve bundles passing to the posterior pallial vessels consist of fibres of the vasomotor system only; it is possible that the muscles of the accessory organ are supplied, in addition to their motor innervation, with fibres of the vasomotor system.

It is pointed out that the elements of the vasomotor system can travel with motor nerves and attention is drawn to the fact that at least one of the main mantle nerves contains ganglion cells belonging to this system.

It is suggested that the function of the organ investigated consists in reducing or stopping the blood flow in the posterior pallial vessels during the more vigorous contractions of the mantle muscles.

\section{REFERENCES}

AleXANDrowicz, J. S., I927. Contribution à l'étude des muscles, des nerfs et du mécanisme de l'accomodation de l'oeil des Céphalopodes. Arch. Zool. exp. gén., Vol. 66, pp. 7I-134.

— 1928. Sur l'innervation des vaisseaux sanguins des Céphalopodes. C.R. Soc. Biol., Paris, T. 99, pp. 1015-16.

- 1960. Innervation of the hearts of Sepia officinalis. Acta zool., Stockh., Bd. 4I, pp. $65-100$.

Ballowitz, E., I892, Ueber den feineren Bau der Muskelsubstanzen. I. Die Muskelfaser der Cephalopoden. Arch. mikr. Anat., Bd. 39, pp. 29I-324.

Bogoraze, D. \& CAZAL, P., I944. Recherches histologiques sur le système nerveux du Poulpe. Arch. Zool. exp. gén., T. 83, pp. 413-44.

BоyсотT, B. B. \& YounG, J. Z., 1956. The subpedunculate body and nerve and other organs associated with the optic tract of cephalopods. Bertil Hanström Zoological Papers, pp. 76-105.

CHÉRON, J., I866. Recherches pour servir à l'histoire du système nerveux des Céphalopodes dibranchiaux. Ann. Sci. nat., Sér. 5, T. 5, pp. 5-I22. 
DAvID, G. B., I955. The effect of eliminating shrinkage artifacts on degenerative changes seen in c.n.s. material. Excerpta med. Amst., Sect. 8, Vol. 8, pp. 777-8.

GaRIAEFF, W., 1909. Zur Histologie des centralen Nervensystems der Cephalopoden. Z. wiss. Zool., Bd. 92, pp. 149-86.

GraziadeI, P., I960. Il corredo nervoso della muscolatura della pinna di Sepia officinalis. Z. ges. Anat. I. Z. Anat. Entw-Gesch., Bd. I21, pp. 393-406.

Hillig, R., I9I2. Das Nervensystem von Sepia officinalis L. Z. wiss. Zool., Bd. Ior, pp. 736-800.

JAKuBSKI, A. W., I9I5. Studien über das Gliagewebe der Mollusken. II. Teil. Cephalopoda. Z. wiss. Zool., Bd. II2, pp. 48-69.

Pfefferkorn, A., 1915. Das Nervensystem der Octopoden. Z. wiss. Zool., Bd. II4, pp. 425-53I.

SERENI, E. \& Young, J. Z., I932. Nervous degeneration and regeneration in Cephalopods. Pubbl. Staz. zool. Napoli, Vol. 12, pp. 173-208.

ThoRe, S., 1939. Beiträge zur Kenntnis der vergleichenden Anatomie des zentralen Nervensystems der dibranchiaten Cephalopoden. Pubbl. Staz. zool. Napoli, Vol. 17, pp. 313-506.

\section{EXPLANATION OF PLATE I-II}

All photographs refer to Sepia officinalis. The preparations were made from specimens of various sizes.

\section{Plate I}

Fig. I. View of the accessory organ stained with methylene blue. The point at which the side branches spring from the pallial artery is unusually distant from the organ (cf. Text-fig. 2). Fig. 2. Transversal section through the accessory organ. Note the difference between the thickness of the wall of the artery (on the right) and that of the vein. The vein is in half distended position; when fully distended it has a diameter markedly larger than the artery. Near the periphery of the organ an arterial branch is cut obliquely. Bouin. Azan.

Fig. 3. Nerves within the accessory organ. Lower right, one of main nerves reaching the organ is seen; others (cf. Text-fig. 3) have been severed at dissection. The dark structure projecting upwards is the artery; the vein has been cut away. Silver impregnation with subsequent bleaching in potassium cyanate solution.

Fig. 4. Section through the accessory organ showing the entrance of one of its motor nerves. Cajal.

\section{Plate II}

All photographs were made under the same magnification. Preparations shown in figs. 5-10 were stained with Bodian's method; in fig. II with methylene blue.

Figs. 5, 6. Motor fibres within the accessory organ. Note the difference in thickness of the fibres.

Fig. 7. Vasomotor nerve within the accessory organ. This nerve in its further course passes on to the artery.

Fig. 8. Nerve in the mantle carrying motor fibres and a vasomotor trunk, the latter seen in the axial position. g.c., ganglion cells. This nerve branches from the main mantle nerve at the point $b$ in Text-fig. 3. The majority of its motor fibres supply the mantle muscles; the vasomotor trunk and few motor fibres penetrate into the accessory organ.

Fig. 9. Nerve within the accessory organ consisting of motor fibres and a bundle of vasomotor fibres,

Fig. 10. Part of a section through the accessory organ with a trunk containing a row of ganglion cells, vasomotor fibres (thin), and motor fibres (thick). This trunk is the continuation of that shown in fig. 8.

Fig. II. Ganglion cells of the vasomotor system from a trunk running into the accessory organ. 

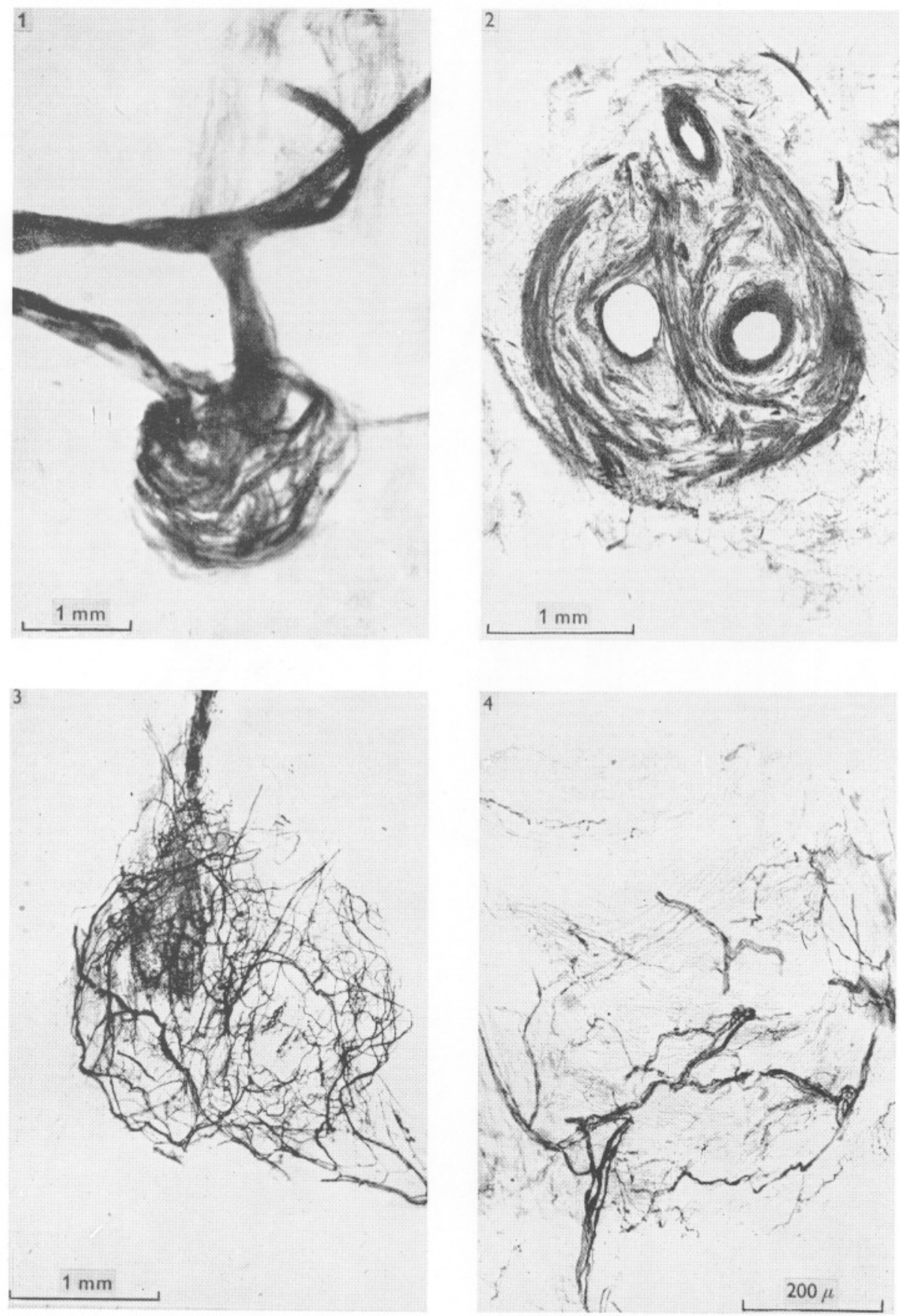

(Facing p. 418) 

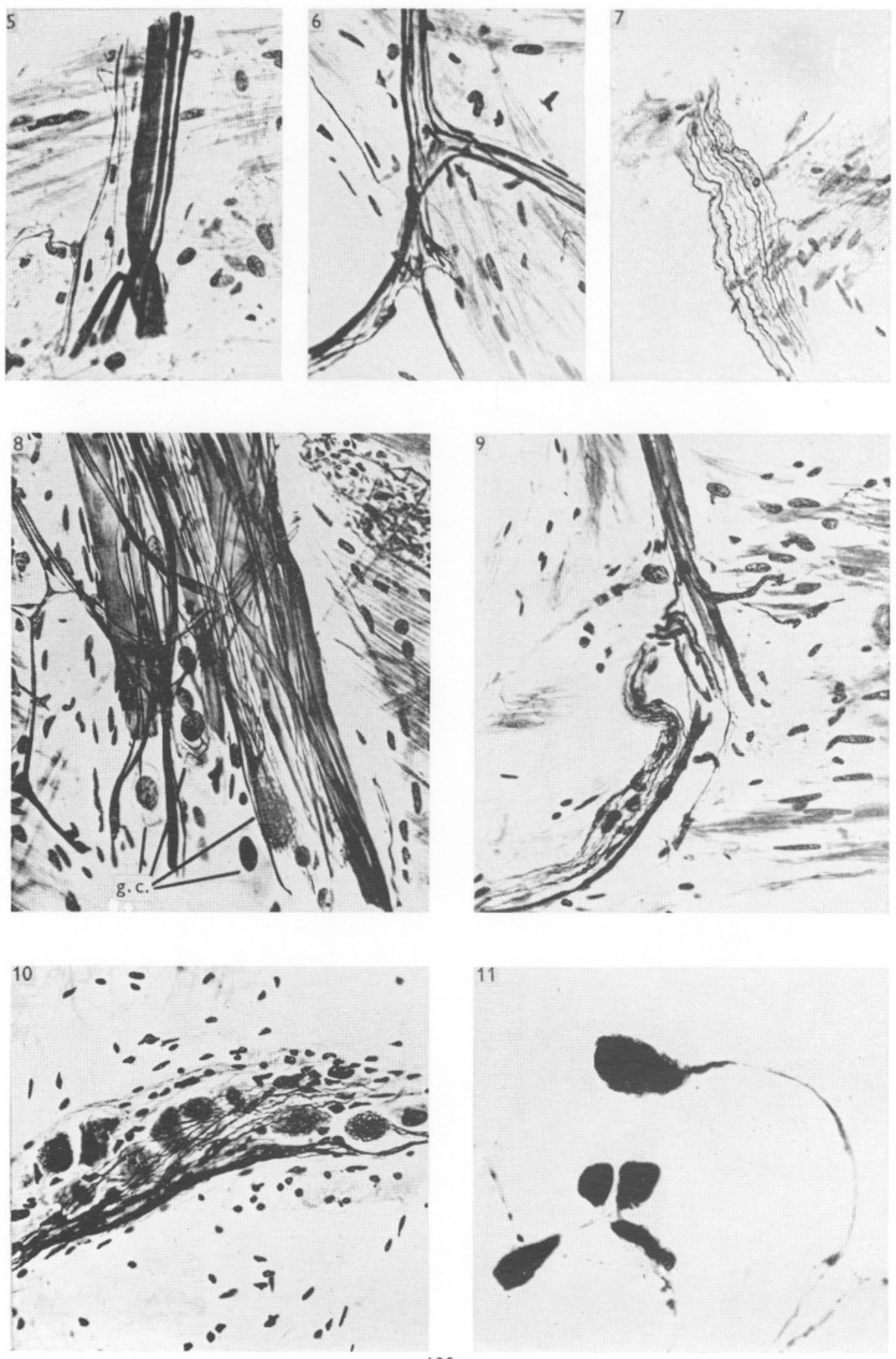